\title{
Respecting Autonomy (Part 2)
}

SADJ August 2018, Vol 73 no 7 p460 - p462

PD Motloba', NL Makwakwa²

\section{AUTONOMY AND OBLIGATION}

Respect for autonomy implies acknowledging that autonomous agents are entitled to hold their own viewpoints, are free to make choices, and act voluntarily according to their values, beliefs and preferences. ${ }^{1}$ Broadly speaking, autonomy includes (i) independence of thought, inclusive of the ability to "think for oneself", make decisions, determine preferences and moral assessment for oneself; (ii) autonomy of will or intention which is regarded as the ability of a moral agent to decide on his/ her plans of actions and activities; and (iii) lastly, autonomy of action, which involves doing what the agent thinks and intends or wills to do. ${ }^{2,3}$ Respecting autonomous agents means acting in a manner that displays a respectful attitude by refraining from interfering in personal affairs, be it what a person thinks, wills, or does., ${ }^{1,2}$ Respecting autonomy means the clinician acknowledges the agency of the patient to exercise the right over all clinical processes undertaken on their person, without undue interference or influence from the attending health care professionals.

As a negative obligation, respect of autonomy requires no external interference or control that would constrain free thought, will and voluntary actions. The question in this regard would be "how far does non-interference extend? Should clinicians in pursuit of this noble virtue still respect the "freedom" of individuals bent at harming themselves, or is there a need to provide some "specifications" or limits on how to respect patient autonomy? As a positive obligation, respect of autonomy encompasses actions and attitudes that encourage autonomous decision-making, and enables the patient's agency to self-determine. ${ }^{4}$ This aspect is symbolised by the Kantian argument that states that we should "...treat others not as means towards some ends, but as ends in themselves." $1,5,6$ It is thus obligatory to capacitate and encourage others to reach their own ends.

As derivatives of the positive and negative obligations of autonomy, certain moral rules have been established as guiding principles to promote and achieve the autonomy

1. Pagollang D Motloba: BDS (Medunsa), MPH (Epidemiology) (Tulane), M Dent (Comm Dent) (Medunsa), MBL (Unisa). Chief Specialist, Head of Department, Community Dentistry, School of Oral Health Sciences - Sefako Makgatho Health Science University.

2. Nokukhanya L Makwakwa: BDT, BDS (Medunsa) Postgraduate Dip in Clinical Dentistry (UWC), MPH (UL). Registrar, Community Dentistry, School of Oral Health Sciences - Sefako Makgatho Health Science University.

Corresponding author

Pagollang D Motloba:

Chief Specialist, Head of Department, Community Dentistry, School of

Oral Health Sciences, Sefako Makgatho Health Science University.

Tel: +27 12521 4848. Email: pagollang.motloba@smu.ac.za of the patient. For example, veracity, protection of privacy, confidentiality and the need to obtain informed consent prior to intervention, are some applications of the respect for autonomy. ${ }^{7,8}$ The debate over the prima facie status of the principle of autonomy over beneficence, non maleficence and justice, rages on. There are grounds for this principle to be overridden by competing moral ideologies, such as beneficence and non-maleficence. For instance, public health programmes and policies such as water fluoridation, vaccination, and quarantine, are justified as moral acts aimed at protecting the public while nevertheless infringing on individual autonomy. ${ }^{9}$ Similarly, a surgeon who deliberately lies to an anxious 16 -year-old patient about their serious health status, is definitely infringing on the patient's autonomy. However, the principle of beneficence might be invoked to justify the doctor's action if such actions could prevent further harm.

Given that persons cannot be prevented from exercising their autonomy, can they be encouraged to make choices? There is no consensus about the nature and extent of this form of encouragement to decision making. Within the clinical environment, patients are subjected to persuasion, inducement and coercion in decision making. It is obligatory to provide persons with all the relevant information, notwithstanding that they might accept or decline to receive or even use the information given. Ultimately it is a violation of the obligation to respect autonomy to compel persons to act on the information provided. In other words, it is a duty to recognise the rights of an autonomous person, as well as to respect their capacity to exercise the right to choose whatever they desire.

\section{CAPACITY, COMPETENCE AND DECISION- MAKING}

Can patients revoke the decisions they made previously? Similarly, can patients change or refuse the type of treatment recommended during the course of the delivery of care? These questions centre on the concept of capacity and competence to make rational decisions.

The terms capacity and competence are used interchangeably despite having distinct legal and normative meanings and application. Strictly speaking, capacity refers to the "The ability to understand information relevant to a treatment decision and to appreciate the reasonably foreseeable consequences of a decision or lack of a decision." ${ }^{10}$ Applied to a health care setting, capacity means that a person has an adequate degree of understanding and a reasonable ability for medical decision-making.

Capacity is specific to a specific situation and time. For example, a patient may have reasonable understanding 
of dental extraction as compared with marsupialisation of an odontogenic keratocyst. Similarly, and over passage of time, it is possible for patients to develop and achieve a reasonable understanding of more complex medical interventions such as marsupialisation.

It is well-established principle in law and morality that capable patients are able to consent freely for treatment. Informed consent supports and validates the ethical principles of autonomy, beneficence and nonmaleficence. ${ }^{1,11}$ First, patients are provided with adequate information to enable free and uncontrolled decisionmaking. Informed and empowered patients are generally able to judge and determine what is in their best interest or not. In case of incapable patients, the principle of autonomy is inapplicable. However, these patients should be protected from inducing self-harm.

The preferences and desires of patients change over time, meaning that their perception of current treatment might change in future. With passing time, the individual's cognitive, psychological, intellectual and legal capacities change, similarly his/her expectations, preferences and choices of the treatment(s) will change. This makes judgment of competence difficult in clinical situations. The fundamental question around competence is what standard or criteria should be met in order to declare a patient capable of autonomous decision-making.

\section{CASE 1}

A flamboyant, 28 year old movie star, who is accompanied by his fiancé, arrives at your practice requiring your intervention. Following his religious beliefs, he has almost succeeded in pulling out his maxillary central incisors. The primary reason for the consultation is that he is worried about bleeding and pain. Is this behaviour bizarre and indicative of incompetence or incoherence? Are persons with unorthodox beliefs therefore less competent? And how is their autonomy and agency guaranteed or respected by practitioners who might have a different persuasion?

The legal framework, and presumed clinical and moral standpoint, is that an adult patient is competent and should be treated as such until otherwise determined. Paradoxically, one should evaluate the level of incompetence to determine competence. The most consistent feature in measures of competence is the mental faculty, characterised by cognitive capacity and independence of judgment.10,12 Therefore ability is tested across a range of standards to express incompetence. Standard questions for evaluation of competence or lack thereof include the following:

1. (In) ability to understand one's situation (medical problem), its consequences, proposed treatment and alternatives.

2. (In) ability to provide rational reasons pertaining to risk/ benefit of proposed treatment for decision to accept or refuse.

3. (In) ability to express and communicate one's preference or choice.

4. (In) ability to make decision freely and autonomously. Tests can be designed to corroborate a certain point of view or judgment. Therefore, it is critical to include criteria that are relevant and have been tested in determining competence. Failure to design contextually appropriate tests would serve to validate any normative views of doctors. Such practices compromise the validity of a test and engender normative prejudices.

There is a need for clinicians to test for competence using any standard measure that is empirically sound and normatively appropriate.

\section{CONSENT AND AUTONOMY}

What does it mean to give consent? And how is consenting an exercise of the right to autonomous decision-making? According to the Oxford Dictionary consent means "permission for something to happen or agreement to do something". Seeking informed consent means that the doctor requests authorisation for a medical procedure that the patient fully understands and agrees with. Anything beyond the contracted agreement is a violation of informed consent. For example, a dentist may not unilaterally or intra-operatively undertake further treatment, unless previously agreed with the patient to do so. For clinicians seeking consent means conforming to the legal and ethical obligations of the profession.

Informed consent cannot be equated to shared decisionmaking, which is often times an informal exchange of information; a casual and asymmetrical communication aimed at getting the patient to choose an intervention among the provided options. Informed consent cannot be reduced to a mere compliance exercise of obtaining authorisation or approval for treatment. Failure to engage patients as equal partners throughout the entire "process" of decision-making is tantamount to medical paternalism. ${ }^{13}$

Hence, it is critical for the health care provider to be aware of several forms of consent. Generally, consent should be expressed explicitly as acceptance or refusal of the suggested intervention over the entire duration of care. However, it is possible for patients or clients to agree or to give general consent for their treatment, implying that any further care would continue without the need to confirm with the patient. In some instances, patients might passively agree or not refuse the treatment suggested; such actions can be construed as tacit consent. ${ }^{14}$

Sometimes a gravely sick patient may receive treatment based on their known history of care and preferences. It is logical and intuitive for doctors to assume that patients would agree to the proposed care based on the medical history, familiarity and trust. Yet, there is a great danger for doctors to impose their wishes and preferences if the patient's voice is not considered at critical times during treatment. Strictly speaking, consent should be based on what the individual actually chooses or prefers, as opposed to what is presumed to be their choice or preferences. Whether general consent is sufficient or specific or necessary depends entirely on the situation at hand. When undertaking invasive and high-risk interventions, it is advisable to seek specific consent from competent persons than not to seek any authority from patients.

\section{IMPLICATION FOR PROFESSIONALS}

Health professionals should make it routine to seek truly informed consent before undertaking any treatment. It is 
advisable to follow the process described below as the necessary elements of consent:

1. Evaluation of Competence: before any information is disclosed and consent is sought, the practitioner needs to ensure that the patient is competent to engage with the process.

2. Disclosure: providing essential and materially critical information to the patient constitutes a major condition for informed consent. How much information is disclosed is dependent on the (i) the standard practiced by the profession; (ii) the standard referenced to a hypothetical reasonable person and (iii) the standard premised on individualism. It is prudent to apply the standard of the reasonable man first before advancing to individualised criteria. There are clinical scenarios wherein intentional non-disclosure may be justified as being beneficial to the patient.

3. Understanding: There is no consensus in literature about the nature and degree or level of understanding required for informed consent. Suffice that understanding of pertinent and central facts to the case is sufficient. Complete understanding is not necessary. Clinicians need to enable sufficient processing of information provided to improve comprehension. Information overload and excessive use of unfamiliar medical jargon are among the commonest mistakes that impede understanding.

4. Voluntariness: Implies that the patient "should be situated as to be able to exercise free power of choice, without intervention of any element of force, fraud, deceit, duress, over-reaching or other ulterior form of constraint or coercion". It is often difficult to distinguish between gentle forms of influence and undue and unjustified influence. Generally, practitioners are expected to abstain from any influence that could impact on the free and voluntary decision-making by patients.

5. Consent: Clinicians are generally oblivious to the all possibilities associated with the communication by a patient of "informed consent ". Informed refusal should be expected just as much as clinicians would expect a decision in favour of the proposed treatment plan.

\section{CONCLUSION}

It is a moral and legal obligation for the clinicians to respect the autonomy of the patient and his/her right to decision making. However, and given that autonomy does not supersede other principles, the decision to respect autonomy should be considered alongside other ethical principles and moral theories.

\section{References}

1. Beauchamp TL, Childress JF. Principles of Biomedical Ethics. Seventh edition. United States of America. Oxford University Press 2013.

2. Gillon R. Ethics needs principles-four can encompass the rest-and respect for autonomy should be "first among equals". Journal of Medical Ethics 2003;29(5):307-12.

3. Gillon R. Medical ethics: four principles plus attention to scope. British Medical Journal 1994;309(6948):184.

4. Christman J. Autonomy in moral and political philosophy. Stanford Encyclopedia of Philosophy 2008.

5. Sullivan RJ. Immanuel Kant's Moral Theory. Cambridge University Press 1989.

6. Wilson EE. Kant on autonomy and the value of persons. Kantian Review 2013;18(2):241-62.

7. Campbell AV. The virtues (and vices) of the four principles. Journal of Medical Ethics 2003;29(5):292-6.
8. Epstein RM, Peters E. Beyond information: exploring patients' preferences.Jama 2009;302(2):195-7.

9. Clouser KD, Gert B. A critique of principlism. The Journal of Medicine and Philosophy 1990;15(2):219-36.

10. Appelbaum PS. Clinical practice. Assessment of patients' competence to consent to treatment. The New England Journal of Medicine 2007;357(18):1834-40, doi:10.1056/ NEJMcp074045.

11. Nelson RM, Beauchamp T, Miller VA, et al. The concept of voluntary consent. The American Journal of Bioethics 2011;11(8):6-16.

12. Dunn LB, Nowrangi MA, Palmer BW, Jeste DV, Saks ER. Assessing decisional capacity for clinical research or treatment: a review of instruments. American Journal of Psychiatry 2006;163(8):1323-34.

13. Andorno R. The right not to know: an autonomy based approach. Journal of Medical Ethics 2004;30(5):435-9.

14. Moskop JC. Information disclosure and consent: patient preferences and provider responsibilities. The American Journal of Bioethics 2007;7(12):47-9. 